\title{
Root System Radius of Three Cycas Species
}

\author{
Thomas E. Marler and Gil N. Cruz \\ Western Pacific Tropical Research Center, University of Guam, Mangilao, \\ GU 96923
}

Additional index words. Cycas edentata, Cycas micronesica, Cycas nitida, root growth

\begin{abstract}
Knowledge about the position of tree roots is needed to understand tree biology and inform management decisions. Cycad species produce pachycaul stems and are not represented in the published studies on the relationships between aboveground tree traits and root system spread. We measured the radius of root egress from 6-year-old Cycas edentata de Laub., Cycas micronesica K.D. Hill, and Cycas nitida K.D. Hill \& A. Lindstrom plants in an ex situ cycad germplasm collection into an 8-m-wide buffer zone in which no trees were growing. We then determined the relationships of root system radius to aboveground plant traits. The root system radius extended 5.2 to $7.5 \mathrm{~m}$ from the base of the stems, and was 3.5 times the plant height, 32 to 36 times the stem diameter, and 3.6 to 4.2 times the radius of the canopy dripline. Values for root radius in relation to plant height and canopy radius exceeded published data for leptocaul tree species, but values for stem diameter were less than these data. These findings on the location of cycad roots provide adaptive management cycad knowledge to inform horticulture decisions such as avoidance of roots during soil disturbance and placement of fertilizers and systemic pesticides.
\end{abstract}

Knowledge concerning the lateral spread of tree root systems is important for many horticulture and silviculture objectives. Because of the hidden nature of roots, these traits are rarely studied, especially for large trees. The limited number of studies on this subject have focused on aboveground tree traits that correlate with root spread. Tree height may be useful for some species to estimate root spread, with root radius estimates of 1.0 to 1.5 times the tree height (Day et al., 2010). The diameter of the canopy dripline has been used as a predictor for root spread, with most estimates of root spread of about three times the canopy diameter (Day et al., 2010; Gilman, 1988, 1989; Gilman et al., 1987; Watson and Himelick, 1982). Trunk diameter has also been used to estimate root spread, with a root radius estimated at about 38 times the diameter of the trunk at breast height (Day et al., 2010; Gerhold and Johnson, 2003; Gilman, 1989). Although the trunk diameter may be the most reliable predictor among these three aboveground traits (Day and Wiseman, 2009; Day et al., 2010), the differences among the species that have been studied to date indicate the scaling relationships may not be canonical, and data should be

Received for publication 18 Oct. 2021. Accepted for publication 18 Nov. 2021.

Published online 17 January 2022.

This research was funded in part by the U.S. Forest Service (grant nos. 13-DG-11052021-210 and 17-DG-11052021-217).

We thank Rodelyn Maravilla for nursery maintenance and Gerard Sigua for providing field labor.

T.E.M. is the corresponding author. E-mail: marler. uog@gmail.com.

This is an open access article distributed under the CC BY-NC-ND license (https://creativecommons. org/licenses/by-nc-nd/4.0/). collected for each tree species to enable the most accurate knowledge for informing management decisions.

One utilitarian need for understanding root spread of managed trees is improving the accuracy of specific horticulture and silviculture applications such as fertilizer or systemic pesticides. The need for an understanding of root spread for Guam's C. micronesica has recently emerged as a result of the listing of the species under the Endangered Species Act (ESA) (U.S. Fish \& Wildlife Service, 2015). The greatest threat to this gymnosperm tree is lethal infestations of the nonnative armored scale Aulacaspis yasumatsui Takagi (Marler, 2012). After the 2003 invasion of this scale, the mortality of Guam's once-abundant $C$. micronesica population reached $92 \%$ by 2011 (Marler and Lawrence, 2012) and $96 \%$ by 2020 (Marler and Krishnapillai, 2020). Ongoing active management of in situ conservation plots that were constructed in 2014 requires mitigation of all known threats within the plots (Marler et al., 2016b). The management plan for these plots required the application of systemic insecticides to control temporarily the $A$. yasumatsui infestations while the conservation community waits for responsible funding agencies to fund the establishment of an effective biological control program. Decision makers need knowledge of estimated root spread of this tree species to apply the prescribed insecticides accurately and to ensure best management practices are honored.

The literature describing aboveground traits that correlate with the root spread of trees is restricted to leptocaul (sensu Hallé et al., 1978) lignophyte tree species. Cycads form a pachycaul stem growth habit, so the allometric relationships of various plant organs described in the leptocaul literature may not reflect those of cycad tree species accurately (Niklas et al., 2006). This paucity of cycad research in the applied sciences often constrains cycad-specific knowledge (Cascasan and Marler, 2016; Norstog and Nicholls, 1997). We exploited a recent opportunity when a cycad germplasm collection was transplanted from one field location to a second location to excavate some of the roots that were left behind after transplanting. Our objectives were to determine the relationships among various aboveground plant traits and the lateral spread of root systems for three Cycas species after the plants were growing in an open field for 4 years.

\section{Materials and Methods}

The nursery phase of this study was conducted in Barangay Malabañas, Angeles City, Philippines. Seeds from various cycad species were collected from January through June 2011. The sarcotesta was removed from the seeds immediately after harvest, and was incubated in ambient conditions for embryo maturation. All seeds were planted in a nursery bed comprised of horticultural perlite on 25 Aug. 2011. The bed was covered with shadecloth to exclude $80 \%$ of incident sunlight, and was irrigated two to three times per week. Seedlings were removed from the bed as each seed germinated and were planted individually in 2.6-L containers with washed river sand as the growing medium. This phase lasted from Oct. through Nov. 2011. The plants were transferred to 5.1-L containers in Oct. 2012. The nursery plants were irrigated as needed and fertilized with complete soluble fertilizer every 2 months.

The entire germplasm collection was transplanted to a field site in Barangay Manibaug Libutad, Porac, Philippines in June 2013. The soil was a young Entisol (sandy, mixed, isohyperthermic, Typic Psammaquent) with a $\mathrm{pH}$ of 6.7. The site was an abandoned sugarcane farm. Planting holes were dug by hand. Most of the germplasm was planted in a $2 \times 3-\mathrm{m}$ grid, but a border row at the garden site was planted at a spacing of $3 \mathrm{~m}$ and provided an 8-m buffer zone of open space for unrestricted root egress away from the border row. No irrigation or fertilization was provided, but weed growth was suppressed mechanically at $\approx 2$-month intervals.

The entire collection was transplanted to an alternative conservation site in Barangay Sapang Bato, Angeles City, Philippines in June through July 2017. The robust plants were 6 years old and had been growing in the field site for 4 years (Fig. 1A). The three species included in this root study were the closely related $C$. edentata, $C$. micronesica, and $C$. nitida. The $C$. edentata plants were sourced from Pinamalayan, Oriental Mindoro, Philippines. The C. micronesica plants were sourced from Colonia, Yap, Federated States of Micronesia. The $C$. nitida plants were sourced from Calbayog, Samar, Philippines. 


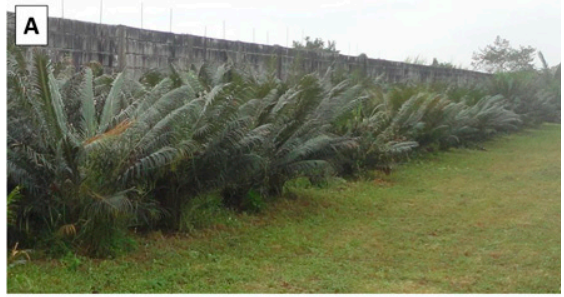

B

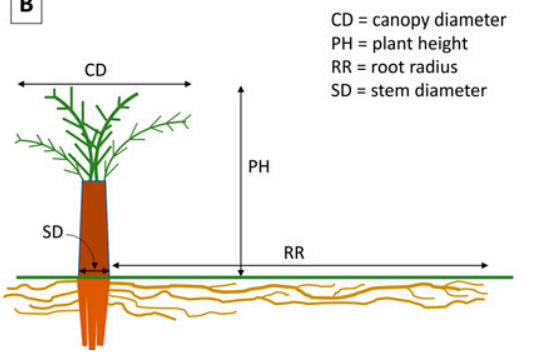

Fig. 1. (A) Appearance of robust 6-year-old Cycas plants that were excavated in March through April 2017, showing 8-m-wide open space for root egress. (B) Schematic of the plant traits that were measured. CD, canopy diameter; $\mathrm{PH}$, plant height; $\mathrm{RR}$, root radius; $\mathrm{SD}$, stem diameter.

Exact localities are not reported to conform to conservation protocols.

These developments presented a unique opportunity to determine the maximum length of root egress into the 8-m-wide open space adjacent to the border planting. Plant height, basal stem diameter, and diameter of the canopy drip line were measured for each plant before excavation (Fig. 1B). All leaves were pruned at the base of each petiole in preparation for excavation. Each nuclear root system was excavated intact, within a 50-cm-wide root ball that was retained on the transplanted plants. All roots outside the excavated holes were left undisturbed by this procedure. By starting at the hole and excavating into the open space, the radius of the root system of each replication was determined. Root excavation was accommodated by this unstructured, sandy Entisol, and root overlap of adjacent plants within the 8-m-wide open space was minimal and determined easily by following individual roots that egressed away from the holes. The distance between the center of the excavated hole and the termination of the longest root was measured to the nearest centimeter for each of 10 replications per species. The actual length of each root from the base of each stem was calculated from these data by subtracting the radius of each corresponding stem (Fig. 1B).

The range in vigor among the three species provided a range in plant size of the 6- year-old plants. The various response variables were subjected to one-way analysis of variance (PROC GLM Version 9.4; SAS Institute, Cary, NC). Tukey's honestly significant difference test was used for pairwise comparisons for significant response variables. The root system radius for each species was regressed onto plant height, basal stem diameter, and radius of the canopy drip line to compare these traits with the literature (PROC GLM).

\section{Results}

Six-year-old Cycas plants exhibited a mean lateral root system radius of 5.5 to 7.2 $\mathrm{m}$ (Table 1). Cycas edentata exhibited greater aboveground growth than $C$. micronesica or C. nitida, and also exhibited the greatest root spread. Cycas micronesica exhibited the least vigor in this ex situ collection, which may reflect the fact that the species is not native to the Philippines.

The root system radius of $C$. micronesica plants was $77 \%$ of that for $C$. edentata, with the radius of $C$. nitida being intermediate $\left(F_{2,27}=\right.$ 77.36, $P \leq 0.001)$. A similar ranking of the three species occurred for plant height; height for $C$. micronesica plants was $81 \%$ of that for C. edentata $\left(F_{2,27}=20.84, P \leq 0.001\right)$. The root system radius was about 3.5 times the plant height. The stem diameter of $C$. micronesica plants was $73 \%$ of that of $C$. edentata $\left(F_{2,27}=\right.$ $6.89, P=0.004)$. Again, $C$. nitida stem diameter was intermediate. The quotient derived by dividing the root system radius by the stem diameter ranged from about 32 for $C$. edentata to 36 for $C$. nitida. Canopy diameter was less variable among the species than the other response variables, but these differences were significant $\left(F_{2,27}=11.47, P \leq 0.001\right)$. The quotient derived by dividing the root system radius by the canopy radius (half the canopy diameter) ranged from 3.6 for $C$. micronesica to 4.2 for $C$. edentata. These results indicate $2 \%$ to $3 \%$ of the root spread was excavated with the transplanted root balls, and was similar for the three species (Table 1).

Plant height and the root system radius exhibited a linear relationship for all three species (Fig. 2). In contrast, basal stem diameter and the root system radius did not scale linearly for $C$. edentata, but did for the other two species (Fig. 3). The canopy radius and root system radius also exhibited a linear relationship for all three species (Fig. 4).

\section{Discussion}

The relationships among various aboveground plant traits and the extent of belowground root spread are reported for the first time for cycads. Cycads are the most threatened plant group worldwide (Fragniere et al., 2015), so most destructive methods that are needed for conducting applied research are rarely used. The transplantation of our large germplasm collection fortuitously enabled this unique opportunity to excavate portions of the root systems that were left behind after the transplantation.

Our results indicate the root spread in relation to the canopy spread of pachycaul cycad tree species may be greater than that of leptocaul angiosperm tree species, as the root system radius of our plants was about four times the canopy radius. The root spread of leptocaul tree species is, in general, about three times the canopy spread (Day et al., 2010; Gilman, 1988, 1989; Gilman et al., 1987; Watson and Himelick, 1982). Our results indicate that cycad trees may exhibit root spread relative to stem diameter that may be less than that of leptocaul species. The root radius has been estimated to be $\approx 38$ times the diameter of a tree trunk (Day et al., 2010; Gerhold and Johnson, 2003; Gilman, 1989), but our cycad results indicate the value of this relationship this 32 to 36 . Leptocaul tree height has been used for some species to estimate root spread, revealing a 1:1 relationship between root radius and tree height (Day et al., 2010). Our pachycaul cycad stems exhibited a root spread that was 3.5 times the plant height.

Determination of the root extension rate was not one of our objectives; however, the window of time that the plants were growing in the field may be combined with the root radius to estimate the root extension rate for each species. Under the conditions of the 4 years of growth, the $C$. edentata roots expanded at a rate of $3.7 \mathrm{~cm}$ per week, the $C$. micronesica roots expanded at a rate of $2.8 \mathrm{~cm}$ per week, and the C. nitida roots expanded at a rate of 3.3 $\mathrm{cm}$ per week. To our knowledge, these are the first root extension growth rates reported for cycads. Rhizotron studies are required to measure cycad root extension directly.

Two of our species have been the subject of container studies that included roots as one of the organs measured. For two- to four-leaf seedlings of $C$. micronesica, the total root length was 900 to $1400 \mathrm{~cm}$ (Marler et al., 2016a). For four- to six-leaf seedlings of $C$. edentata, total root length was 2000 to 2500 cm (Marler, 2013).

Full interpretation of our results requires consideration of three caveats. First, these cycad data were limited to young plants, so the root spread of older cycad trees remains to be studied. However, our comparisons to

Table 1. Root system radius and aboveground traits of three Cycas species after 4 years of field growth. Mean $\pm \mathrm{SE}, \mathrm{n}=10$.

\begin{tabular}{|c|c|c|c|c|c|}
\hline Species & Root system radius $(\mathrm{cm})$ & Plant ht $(\mathrm{cm})$ & Stem diam $(\mathrm{cm})$ & Canopy diam $(\mathrm{cm})$ & Percent roots not removed ${ }^{\mathrm{z}}$ \\
\hline Cycas edentata & $716 \pm 33 \mathrm{a}^{\mathrm{y}}$ & $203 \pm 3 \mathrm{a}$ & $22 \pm 2 a$ & $342 \pm 6 \mathrm{a}$ & $98.1 \pm 0.1$ \\
\hline Cycas micronesica & $554 \pm 11 \mathrm{c}$ & $164 \pm 5 \mathrm{c}$ & $16 \pm 1 \mathrm{~b}$ & $307 \pm 6 b$ & $96.9 \pm 0.1$ \\
\hline Cycas nitida & $651 \pm 10 b$ & $188 \pm 4 b$ & $18 \pm 1 \mathrm{ab}$ & $328 \pm 5 \mathrm{ab}$ & $97.6 \pm 0.1$ \\
\hline
\end{tabular}

${ }^{\mathrm{z}}$ Percentage of distance from stem to most distal lateral root that was not retained during excavation of plants

${ }^{\mathrm{y}}$ Any two means within a column not followed by the same letter are significantly different at $P \leq 0.05$. 


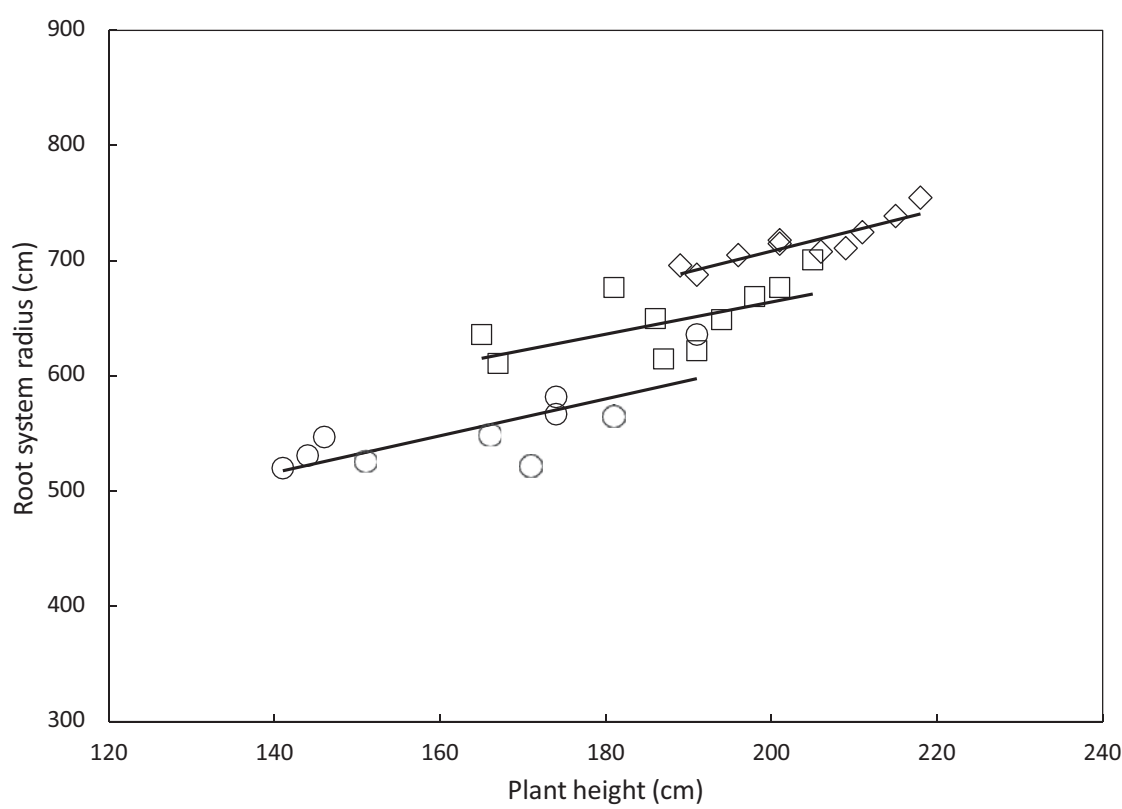

Fig. 2. The relationship of total plant height and root system radius for Cycas edentata (diamonds, $y=$ $\left.348.4+1.8 x, r^{2}=0.81\right)$, Cycas micronesica (circles, $\left.y=292.2+1.6 x, r^{2}=0.64\right)$, and Cycas nitida (squares, $y=384.3+1.4 x, r^{2}=0.42$ ).

leptocaul tree data are justified because the studies that generated most leptocaul published data were also conducted on young trees. Second, our stem diameter data were obtained from the base of each plant's monopodial stem, but most of the published leptocaul data were obtained as diameter at breast height. Our experimental units were not tall enough to be able to measure stem diameter at breast height. Third, our results obtained from an open field ex situ planting are applicable for horticultural settings, but may not

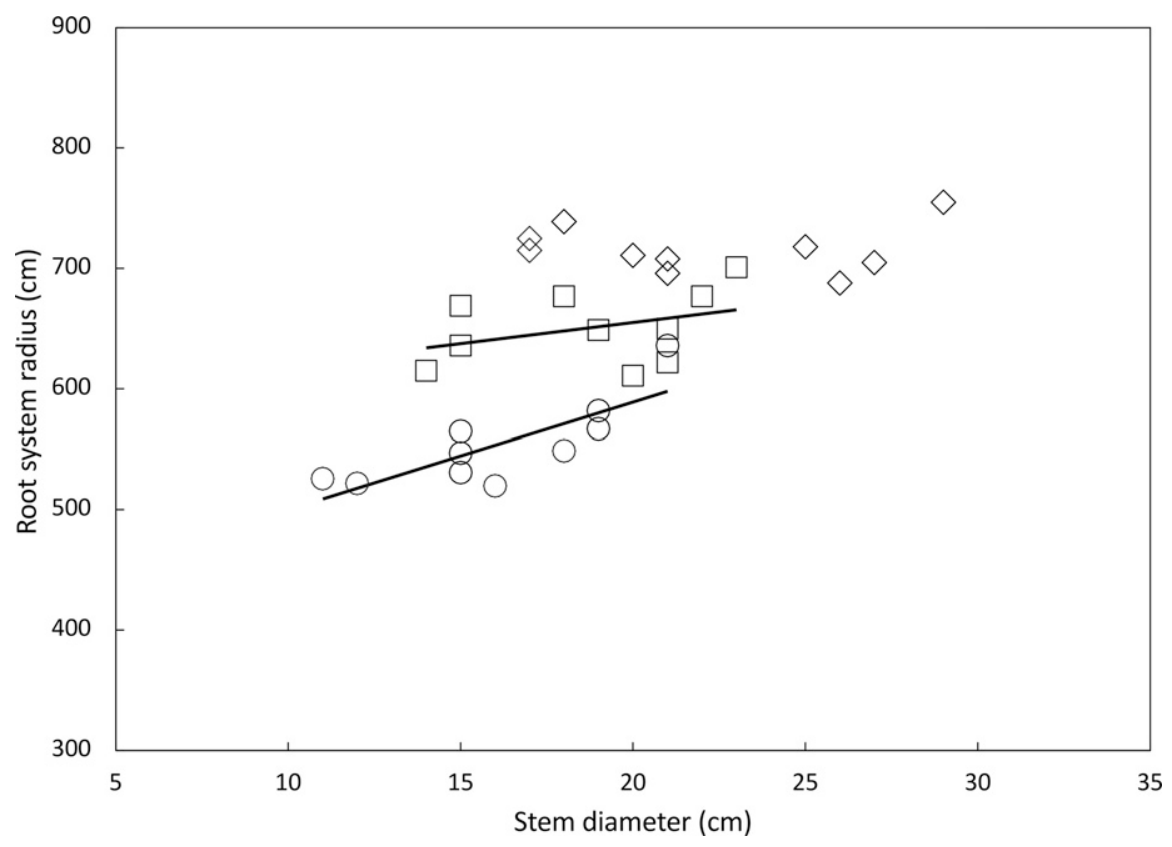

Fig. 3. The relationship of basal stem diameter and root system radius for Cycas edentata (diamonds, regression not significant), Cycas micronesica (circles, $y=411.1+8.9 x, r^{2}=0.64$ ), and Cycas nitida (squares, $y=585.1+3.5 x, r^{2}=0.40$ ).
$3 \%$ of the lateral root spread was retained on the roots that were excavated with the transplanted trees. Transplantation of cycad plants is highly successful provided the stem is healthy and undamaged during the procedure. In our study, $100 \%$ of the plants established successfully in the second location despite the exclusion of $97 \%$ to $98 \%$ of the lateral root spread from the excavated plants at the first location.

Conservation applications. Best management practices are required to meet the terrestrial resource management obligations within U.S. federal lands, and these practices must be grounded in sound science. For Department of Defense lands, the obligations of military resource managers are described in the Sikes Act, which requires the development of an Integrated Natural Resources Management Plan (INRMP) for each region. More species that are listed under the ESA occur on lands under Department of Defense jurisdiction than for any other federal agency (Benton et al., 2008). The management approaches for these ESA-listed species are integral parts of every INRMP.

We were on the team that designed and constructed five disjunct $C$. micronesica in situ management plots in northern Guam to conserve more than 500 mature trees (Marler et al., 2016b). Cycas micronesica is among Guam's tree species that are ESA-listed (U.S. Fish \& Wildlife Service, 2015). Appropriate management of these in situ conservation plots requires decision makers to become fluent in the germane literature to ensure current knowledge informs best management practices. The best management practices for the application of the systemic insecticide imidacloprid to control $A$. yasumatsui within these plots is guided by the fact that tree size must factor into the calculation of dosage. Use of a fixed per-tree application dose would violate the INRMP by dismissing the science of allometry. For example, an arbitrary single tree dose may underadminister the active ingredient for the largest trees, risking failures in protecting the endangered trees from lethal-scale infestations. In contrast, a single dose per tree may overadminister for the smallest trees, risking environmental damage. The imidacloprid literature allowed our calculation of prescribed active ingredient dosage based on trunk diameter, product label specifications allowed algebraic calculations to define the area over which this prescription should be broadcast, then geometric formulae enabled calculation of the custom radius of the circle surrounding each tree to accommodate the prescribed area. These methods determined a radius of $1.8 \mathrm{~m}$ for application to the smallest trees and a radius of $4 \mathrm{~m}$ for application to the largest trees. The mean trunk diameter among the more than 500 trees was $18.3 \mathrm{~cm}$, and the use of our 35:1 formula (calculated from Table 1) for C. micronesica indicated the trees were supported by an estimated mean root system radius of $6.4 \mathrm{~m}$. Therefore, the best available science indicated application of this systemic insecticide to the area surrounding each tree defined by a 2 to 4 $\mathrm{m}$ radius supplied the product to areas well 


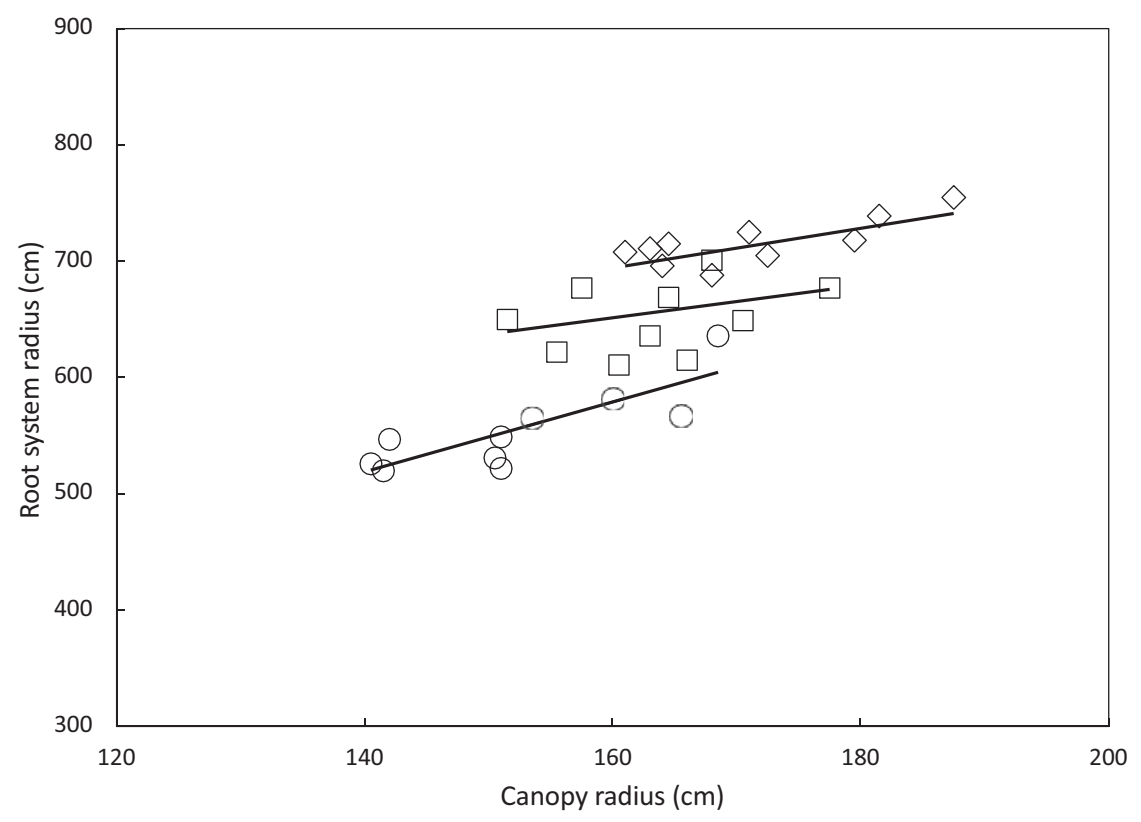

Fig. 4. The relationship of canopy radius and root system radius for Cycas edentata (diamonds, $\left.y=422.3+1.7 x, r^{2}=0.64\right)$, Cycas micronesica (circles, $y=99.1+3.0 x, r^{2}=0.67$ ), and Cycas nitida (squares, $y=427.4+1.4 x, r^{2}=0.35$ ).

within the root zone of each tree, reducing the risk of environmental damage and adhering to the INRMP.

Future directions. Our results illuminate several interesting unanswered questions. First, the sandy Entisol soil and open field space for our study may have generated cycad root growth that differed from root growth in other soils and in biodiverse forests. The influence of soil physical and chemical attributes on the lateral growth of cycad root systems has not been determined. Second, our data were constrained to relatively small 6-year-old plants, so stem diameter was minimal when compared with maximum stem diameter of mature arborescent cycad plants. The published data on the relationship of root system radius and leptocaul stem diameter indicate that the root system radius increases linearly with stem diameter up to about $30 \mathrm{~cm}$, then the root system radius remains similar for stem diameters greater than $30 \mathrm{~cm}$ (Day et al., 2010). Knowledge about the influence of stem diameter on the root system radius has not been determined for large cycad trees. Third, our data were limited to three Cycas species. There are 365 accepted cycad species distributed among 10 accepted genera (Calonje et al., 2021). The relationship between aboveground plant traits and the root system radius remains to be determined for the remaining species and genera. Fourth, the canopy diameter of a monopodial cycad plant is largely determined by the length of the pinnately compound leaves. Our plants were grown in full sun, and cycad plants grown in shaded forest habitats may exhibit leaf lengths much greater
Fragniere, Y., S. Bétrisey, L. Cardinaux, M. Stoffel, and G. Kozlowski. 2015. Fighting their last stand? A global analysis of the distribution and conservation status of gymnosperms. J. Biogeogr. 42:809-820, https://doi.org/10.1111/jbi.12480.

Gerhold, H.D. and A.D. Johnson. 2003. Root dimensions of landscape tree cultivars. J. Arboric. 29:322-326.

Gilman, E.F. 1988. Tree root spread in relation to branch dripline and harvestable root ball HortScience 23:351-353.

Gilman, E.F. 1989. Predicting root spread from trunk diameter and branch spread. Arboric. J. $13: 25-32$.

Gilman, E.F., I.A. Leone, and F.B. Flower. 1987. Effect of soil compaction and oxygen content on vertical and horizontal root distribution. J. Environ. Hort. 5:33-36.

Hallé, F., R.A.A. Oldeman, and P.B. Tomlinson. 1978. Tropical trees and forests. Springer-Verlag, Berlin, Germany.

Mabberley, D.J. 1974. Pachycauly, vessel-elements, islands and the evolution of arborescence in 'herbaceous' families. New Phytol. 73:977-984, https://doi.org/10.1111/j.1469-8137.1974.tb01326.x.

Marler, T.E. 2012. Cycad aulacaspis scale invades the Mariana Islands. Mem. N. Y. Bot. Gard. 106:20-35.

Marler, T.E. 2013. Kin recognition alters root and whole plant growth of split-root Cycas edentata seedlings. HortScience 48:1266-1269, https:// doi.org/10.21273/HORTSCI.48.10.1266.

than our full-sun plants. These plastic traits of leaf size may influence the allometric relationship between cycad canopy diameter and the root system radius to a greater degree than for leptocaul tree species, for which the distance to the canopy drip line is determined primarily by plagiotropic stem growth. Fifth, pachycaul tree species are not restricted to cycads, and the root system radius of the other pachycaul taxa also deserve to be studied. Pachycaul trees are characterized by massive primary construction, relatively few secondary branches, and relatively thick stems (Mabberley, 1974). The greater root system spread relative to plant height and lesser root spread relative to stem diameter that we report for three Cycas species may be allometric traits that are common among all pachycaul species, not just cycads.

\section{Literature Cited}

Benton, N., J.D. Ripley, and F. Powledge (eds.) 2008. Conserving biodiversity on military lands: A guide for natural resources managers NatureServe, Arlington, VA. 17 Nov. 2021. $<$ http://www.dodbiodiversity.org $>$.

Calonje, M., D.W. Stevenson, and R. Osborne. 2021. The world list of cycads. 17 Nov. 2021. $<$ http://cycadlist.org $>$.

Cascasan, A.N. and T.E. Marler. 2016. Publishing trends for the Cycadales, the most threatened plant group. J. Threat. Taxa 8:8575-8582, https://doi.org/10.11609/jott.2369.8.3.8575-8582.

Day, S.D. and P.E. Wiseman. 2009. At the root of it. Arborist News 18(6):20-22.

Day, S.D., P.E. Wiseman, S.B. Dickinson, and J.R. Harris. 2010. Contemporary concepts of root system architecture of urban trees. Arboricult. Urban For. 36:149-159.
Marler, T.E., N. Dongol, and G.N. Cruz. 2016a. Plastic responses mediated by identity recognition in below-ground competition in Cycas micronesica K.D. Hill. Trop. Conserv. Sci. 9:648-657, https://doi.org/10.1177/1940082916 00900206.

Marler, T.E. and M.V. Krishnapillai. 2020. Longitude, forest fragmentation, and plant size influence Cycas micronesica mortality following island insect invasions. Diversity (Basel) 12:194, https://doi.org/10.3390/d12050194.

Marler, T.E. and J.H. Lawrence. 2012. Demography of Cycas micronesica on Guam following introduction of the armoured scale Aulacaspis yasumatsui. J. Trop. Ecol. 28:233-242, https:// doi.org/10.1017/S0266467412000119.

Marler, T.E., J.H. Lawrence, and G.N. Cruz. 2016b. Topographic relief, wind direction, and conservation management decisions influence Cycas micronesica K.D. Hill population damage during tropical cyclone J. Geogr. Nat. Disast. $6: 178, \mathrm{https}: / /$ doi.org/10.4172/2167-0587.10 00178.

Niklas, K.J., E.D. Cobb, and T. Marler. 2006. A comparison between the record height-to-stem diameter allometries of pachycaulis and leptocaulis species. Ann. Bot. 97:79-83, https://doi. org/10.1093/aob/mcj002.

Norstog, K.J. and T.J. Nicholls. 1997. The biology of the cycads. Cornell University Press, Ithaca, NY.

U.S. Fish \& Wildlife Service. 2015. Endangered and threatened wildlife and plants; endangered status for 16 species and threatened status for 7 species in Micronesia. Fed. Regist. 80:59424-59497.

Watson, G.W. and E.B. Himelick. 1982. Root distribution of nursery trees and its relationship to transplanting success. J. Arboric. 8:225-229.

Watson, G.W. and T.D. Snydor. 1987. The effect of root pruning on the root system of nursery trees. J. Arboric. 13:126-130. 